\title{
Spanish Adaptation of the Self- and Other-Interest Inventory in Academic Settings
}

\author{
Raimundo Aguayo-Estremera $^{1}$ (D), Cristina Miragaya-Casillas ${ }^{2}$ (D), Manuel Correa $^{2}$ (D) and \\ Alberto Ruiz-Villaverde ${ }^{2}$ (D) \\ ${ }^{1}$ Universidad Complutense (Spain) \\ ${ }^{2}$ Universidad de Granada (Spain)
}

\begin{abstract}
In the study of human motivations, self-interest is often seen as a determining factor and opposed to otherinterest. Recently a new conceptualization has been proposed in which both interests can occur at the same time. In order to measure these constructs, the Self-and Other-Interest Inventory (SOII; Gerbasi \& Prentice, 2013) was created, which has one version for adults and one for students. Due to the absence of similar measurement instruments in Spain, the aim of this work is to adapt the SOII to Spanish university students. Several studies were conducted. First, the construct was analyzed through rational-analytical procedures. Second, the items were translated following an iterative forward-translation design. Finally, evidence of validity was obtained through analytical procedures. Specifically, two pilot studies were carried out in which two independent samples of Spanish students participated $(N 1=119 ; N 2=165)$. In both studies descriptive analyzes of the items were performed, reliability was estimated and the factor structure of the SOII was explored from an exploratory factor analysis. The results showed adequate reliability and a two-factor solution consistent with the original.
\end{abstract}

Received 31 May 2020; Revised 25 March 2021; Accepted 26 March 2021

Keywords: adaptation, inventory, other-interest, self-interest, SOII

A key issue in academic debate is that which refers to the study of the reasons that determine the behavior of the individual in society. Currently, there is consensus when it comes to understanding that self-interest exerts a powerful influence on individual behavior (Gerbasi \& Prentice, 2013). Many social scientists have been interested in this concept, which has been given different names, for example, selfishness from Psychology (Cialdini, 1991) and self-interest from the Economy (Hirschman, 1997). Despite the differences in specialty and nomenclature, the authors tend to agree on defining it as the pursuit of benefits for the individual, as opposed to the pursuit of benefits for other people (e.g., Hirschman, 1985; Myers \& Twenge, 2017). The pursuit of benefits for other people has also received different conceptualizations, for instance, prosocial

Correspondence concerning this article should be addressed to Manuel Correa. Universidad de Granada. Facultad de Ciencias Económicas y Empresariales. Departamento de Economía Aplicada. Campus de Cartuja, S/N, Facultad de Ciencias Económicas. 18071 Granada (Spain).

E-mail: manuelcorrea@ugr.es

Conflicts of Interest: None.

Funding Statement: This research received no specific grant from any funding agency, commercial or not-for-profit sectors. behavior (Batson et al., 1981), helping behavior (Schroeder et al., 1995), altruism (Batson, 1998; Myers \& Twenge, 2017) and other-interest (Gerbasi \& Prentice, 2013).

Traditionally, researchers have placed self-interest at the center of their explanatory theories, either explicitly or implicitly, neglecting other-interest. However, both psychologists and economists have obtained evidence that these variables related to the pursuit of benefits for others have explanatory power of the behavior of individuals in society. Some of the variables studied include reciprocity and fairness from behavioral economics, helping and prosocial behavior from social psychology and altruism from both disciplines (e.g., Dovidio et al., 2017; Fehr et al., 2002; Fehr \& Gächter, 2000; Schroeder et al., 1995).

In the 1990s, behavioral economists developed explanatory models of individual decision-making

How to cite this article:

Aguayo-Estremera, R., Miragaya-Casillas, C., Correa, M., \& RuizVillaverde, A. (2021). Spanish adaptation of the self- and otherinterest inventory in academic settings. The Spanish Journal of Psychology, 24. e36. Doi:10.1017/SJP.2021.29 
incorporating for the first time social preferences or other-regarding preferences.

The main theoretical modeling attend to three (often interrelated) reasons why individuals might be concerned about other-regarding preferences, namely:

1. Inequality aversion: Individuals would be willing to assume personal costs in exchange for correcting inequality in society. One of the pioneering models that addresses this issue is that of Fehr and Schmidt (1999).

2. Reciprocity: In economic contexts, individuals behave intentionally, emitting signals of goodness in order not to be punished by other individuals or to think of the benefits in terms of future. Rabin's (1993) work is considered the pioneering model of rationalization of altruism based on justice.

3. Feeling of guilt: Individuals may feel bad about disappointing others, which is related to what society expects of people and their behavior. Charness and Dufwenberg's (2006) approach is different from the previous ones and focuses on modeling the notion of guilt in a systematic and general manner.

In addition, the pursuit of self- and other-interest seem to be interrelated and interdependent. Regarding its relation, factors have been observed that modify selfand other-interested behaviors; for example, not having a clear context of cost-benefit analysis, situations that have a personal impact or situations in which people understand that they should be self-interested (Gerbasi \& Prentice, 2013). In this sense, Schroeder et al. (1995) found that the probability of being self-interested is greater to the extent that the costs of behaving prosocially are less than the benefits. Regarding the interdependence, individuals have to deal, negotiate, and collaborate with other people, which create an incentive to be attentive to others' interests. This has been observed in economic research on behavior in strategy games (Camarer \& Thaler, 1995; Thaler, 1988). These findings are not consistent with the traditional definition of self-interest, since participants were interested in both their own and the other player's results.

All of the above indicates that, contrary to what is traditionally advocated, the human motivation underlying self-interested behavior does not exclude the pursuit of the interest of others. In addition, it suggests that self- and other-interest can be conceptualized in a common theoretical framework that intends to explain human behavior in society. In this sense, Gerbasi and Prentice (2013) propose that self- and other-interest are different constructs, related to each other but not necessarily in opposed directions. Thus, they assume the interdependence between both types of interest as one of the factors underlying human motivation. The mode in which self- and other-interest are materialized in behavior seems to be similar. Both interests are regulated by a conscious and deliberative process, in which personal needs, values, feelings, and aspirations play an important role in assessing the costs and benefits of individual behaviors.

According to this view, Gerbasi and Prentice (2013) proposed a theoretical model of two facets, which has the advantage that it overcomes the problem of assuming the centrality of self-interest in the explanation of human behavior.

From this theoretical model, they have developed a measurement instrument, the Self- and Other-Interest Inventory (SOII), which evaluates both self- and otherinterested behaviors without assuming a concrete relation of dependence among the constructs.

The SOII was created with the aim of evaluating these constructs in both adult and university students in the United States. The operational definition of self-interest refers to the pursuit of gains in socially valued domains, including material goods, social status, recognition, academic or occupational achievement, and happiness. Conversely, the operational definition of the otherinterest refers to the pursuit of gains for others in socially valued domains, including material goods, social status, recognition, academic or occupational achievement, and happiness. The conceptual definition includes opposite relations for self-interest and other-interest with constructs, such as personal values (e.g., materialism, hedonism, security, and achievement), personality (e.g., extraversion, conscientiousness), prosocial behavior, and empathy. A more comprehensive description of these definitions can be found in Gerbasi and Prentice (2013).

The SOII offers the following advantages as a measurement instrument, in comparison to other methods such as economic games (e.g., prisoner's dilemma): (i) It has shown good psychometric properties, both in terms of internal validity and reliability (Gerbasi \& Prentice, 2013); (ii) it does not assume a certain relationship between self- and other-interest; and, (iii) it does not assume self-interest as the central and only explanatory factor of individual behavior.

However, the adaptation to Spanish population has not yet been developed. In the search of scientific literature, no other test measuring self- and other-interest has been found. Hence, the aim of the present study is two-fold: (i) To present the details of the adaptation process of the SOII in Spanish university students; and, (ii) to show initial evidence of equivalence between the original and the adapted version, as well as of some psychometric properties.

This adaptation is expected to serve social scientistsespecially psychologists and economists - in the research of the individual behavior in society. Specifically, this study will help: (i) To improve the lack of 
availability of valid and reliable instruments adapted to Spanish that evaluate these constructs; (ii) to extend the population under study to the Spanish context, allowing the measurement of behavioral differences among university students; (iii) to overcome the traditional conceptualization of self-interest as central and unique in individual behavioral research; (iv) to progress in the measurement of the construct by suppressing the relations determined a priori between both variables; and, (v) to compare self- and other-interest between Spain and the United States. For instance, in standard economics, there is an open debate about whether students with economic training behave in a self-interested manner. The adaptation of SOII may play a key role in obtaining further knowledge in this topic by comparing self- and other-interest in students in different academic degrees and testing indoctrination and selection effects. In Psychology, this adaptation may help to broaden our knowledge in topics such as social psychology by analyzing relationships between several attributes (e.g., social values orientation, personality traits, and helping behavior), and in cross-cultural research by comparing these attributes in different countries.

\section{Method}

According to Ato et al. (2013), the present study is instrumental. In order to carry out the adaptation, the guidelines of the International Test Commission (ITC; 2018) and Muñiz et al. (2013) along with the recommendations of Balluerka et al. (2007), Elosua et al. (2014) and Izquierdo et al. (2014) have been followed.

\section{Participants}

During the empirical phase of the adaptation, two independent samples of subjects were used to analyze some psychometric properties in two pilot studies. The reason for the second study was the refining of some unsatisfactory aspects. In the first study, a total of 119 first-year students from the University of Granada participated (45 men and 72 women). The mean age was $18.9(S D=2.13) .66 \%$ of the participants were Business Administration students; and, the remaining 34\% Business Administration \& Law students (which is a double Degree in Spain). In the second study, a total of 165 individuals from the University of Granada participated (59 men and 102 women), different from those of the first pilot. The mean age was $19.17(S D=2.44) .79 .4 \%$ were firstyear students and the rest, second-year students. 23.6\% belonged to Business Administration, 23\% to Accounting \& Finance, $34.5 \%$ to Psychology and $18.2 \%$ to Criminology.

\section{Instruments}

The student version of the SOII consists of 18 items of which half measure self-interest and the other half measure other-interest. Respondents are asked about their degree of agreement with respect to each of the 18 items using a seven-point Likert rating scale $(1=$ Completely disagree; 7 = Completely agree).

The operational definition of the construct is reflected in the items of the questionnaire. On the one hand, selfinterest refers to the pursuit of personal gains in certain socially valued domains while, on the other hand, otherinterest refers to the pursuit of gains for others in those same aspects. These socially valued domains are material goods, social status, recognition, academic or professional achievements and happiness. The SOII items are designed to be indicators of these; each socially valued domain is related mainly to one item (e.g., "Having a lot of money is one of my goals in life" is an indicator of material goods). However, recognition seems to be related to two items ("Hearing others praise me is something I look forward to" and "I try to make sure others know about my successes"). Additionally, there are three general items ("Success is important to me", "I keep an eye out for my interests", and "I am constantly looking for ways to get ahead"). Additionally, the SOII items assess every socially valued domain for self-interest as well as for other-interest behaviors with a very similar wording. Thus, the items can be viewed as if they would form pairs (regarding selfand other-interest). For example, the pair A7-O3 measures the social status domain. Items can be consulted in the Appendix 1.

In addition to the SOII, a questionnaire with sociodemographic data (age, sex, degree and course) was administered.

\section{Procedure}

Participants were selected through non-random sampling. Questionnaires were administered having previously agreed to the instructions and the collection procedure. The procedure was carried out during class time in a group manner. The data from the first pilot study was collected in June 2018. After analyzing the results, some psychometric deficiencies were detected which needed to be overcome. Therefore, after introducing some changes in the inventory, another data collection was carried out in October 2018. During the process, the execution time was controlled, it was verified that the items and the instructions were correctly understood.

The characteristics of the construct to be measured in the target population were studied. To this end, a literature review on the construct was carried out in different cultures, and the nomological networks related to 
self- and other-interest in the United States and Spain were studied. This literature review included a theoretical study (Urbina \& Ruiz-Villaverde, 2019) and a systematic search for tests that assess self- or other-interest. The search was performed in three electronic databases (Web of Science, Scopus and Proquest) and the generic search equation was ["self interest" OR "other interest" OR "selfishness" OR "egotism" OR "egoism" OR "other interest" OR "social value?" OR "altruism" OR "prosocial" AND test? OR scale? OR inventor* OR survey? OR questionnaire?]. The only field restriction was that the key search terms were restricted to the title of the paper (the different search equations specific to each database can be consulted on request).

Additionally, we used the tool Semantic Scale Network (SSN; Rosenbusch et al., 2020), whose purpose is to automatically detect semantic overlap between scales through Latent Semantic Analysis. According to Rosenbusch et al. (2020), the SNN can be used to search for relevant scales not based on construct names, but item content. Automatic semantic analyses are suitable to support expert evaluations in finding and evaluating scale similarities.

\section{Statistic Analysis}

For both pilot studies, descriptive indices of the items were estimated; in particular, the mean and the standard deviation, the frequencies distribution of the item alternatives and the discrimination index. In order to obtain indications that the adaptation works similarly to the original, several analyzes were performed. First, the quartiles of the discrimination index distributions were calculated. Second, the discrimination indices of the original were compared using minimal-effects tests to ensure they were not higher than those of the adaptation. A description of the minimal-effects tests can be found in Murphy et al. (2014). Subsequently, Exploratory Factor Analysis (EFA) was carried out, based on the Pearson correlation matrices. We perform EFA since the SOII is a very novel measurement instrument and there is only one study that assesses its factor structure. In this scenario, we were not able to establish many of the specifications of confirmatory factor analyses (e.g., the pattern of relationships between the common factors and the indicators, and indicator unique variances). According to the recommendations followed (Bandalos, 2018; Izquierdo et al., 2014; Lloret-Segura et al., 2014), the number of factors to be selected was determined by combining the parallel analysis procedures (Timmerman \& Lorenzo-Seva, 2011), matrix of partial correlations (MAP; Velicer, 1976), very simple structure (VSS; Revelle \& Rocklin, 1979), and Bayesian information criterion (BIC; Schwarz, 1978). The assumptions of univariate normality were verified through the asymmetry and kurtosis indices. The assumptions of multivariate normality through the Mardia's test (Mardia, 1970). Pearson's bivariate correlation matrix was used, since neither asymmetry nor kurtosis were too high (Lloret-Segura et al., 2014) and the response scale contains seven points (Lozano et al., 2008). The Unweighted Least Squares method (ULS) was used as the factor estimation method, due to the non-fulfillment of the multivariate normality assumption, the case of kurtosis, the deviations of univariate normality of some items and the relatively small sample size. This method seems to work well with small samples and a low number of factors to be retained (Lloret-Segura et al., 2014). In order to obtain a final solution, several oblique rotations were attempted (Izquierdo et al., 2014, LloretSegura et al., 2014), with Promin and Promax being the most favorable and very similar among them. According to the recommendations by Ferrando and LorenzoSeva (2013), EFA models were assessed through the fit indices RMSEA, RSMR and GFI, along with the exploration of the standardized residuals.

The statistical analyzes were done with $\mathrm{R}$ ( $\mathrm{R}$ Core Team, 2018), specifically, with the psych (Revelle, 2020, cocor (Diedenhofen \& Musch, 2015), and prettyR (Lemon \& Grosjean, 2015) packages. The EFA was carried out with Factor (Lorenzo-Seva \& Ferrando, 2013).

\section{Results}

The organization of this section follows the three general categories in which the first steps for adapting tests are grouped (previous aspects and development of adaptation), using analytical-rational and empirical procedures (Elosua et al., 2014; Muñiz et al., 2013). Firstly, the aspects prior to the adaptation process are described; secondly, the cultural and linguistic adaptation procedures; and, finally, the piloting phase. The previous aspects, as well as the cultural and linguistic adaptation, refer to the first study goal; the piloting phase refers to the second goal.

\section{Previous Aspects}

In the first place, compliance with the legal aspects was guaranteed. For this purpose, the authors of the original SOII were contacted in order to obtain their authorization to carry out the adaptation. In addition, the basic principles for human research were taken into account. In doing so, the following documents were prepared: A report in which the study is presented and a consent model for the participants. Both documents were sent to the Ethics Committee of the University of Granada in order to obtain the certificate that guarantees that the aforementioned ethical principles have been followed (available upon request). 
Secondly, the characteristics of the construct to be measured in the target population were studied. The literature review search in electronic databases yielded 54 records. The inspection of these records showed there were no tests for the Spanish population. Additionally, the search in the Semantic Scale Network suggested that there are no other tests showing semantic overlap with the SOII.

From the theoretical study of Urbina and RuizVillaverde (2019) it follows that self-interest is a construct linked specifically to individualism (as the individual's predominant attention to the consequences for himself of any contemplated action) and to the rational calculation (as a systematic attempt to evaluate potential costs, benefits, satisfactions and the like). From the field of Behavioral Economics, by employing economic experiments (e.g., ultimatum game, free rider experiment, etc.), empirical evidence has been found of the relationships among these variables (see for example Camerer, 2011, Frank et al., 1993 or Frey \& Meier, 2003). From Social Psychology, using non-experimental methods, a relationship between self-interest and other variables has been observed, for example, low levels of altruism, prosocial behavior and extraversion. Regarding the relationship between self- and other-interest, positive correlations of moderate magnitude have been obtained (Gerbasi \& Prentice, 2013). Evidence from the review of these studies suggests that the overlap of the construct is similar between Spain and the United States.

\section{Cultural and Linguistic Adaptation}

A forward iterative design was first perform, with two versions translated independently. The adaptation team consisted of two independent professional translators, natives of the culture of origin with experience in scientific translation, and two experts in the topic of this research, one in psychometrics and the other in substantive aspects. Both experts are native to the target culture and have a high level of knowledge in English. In the first place, the two translators were urged to separately carry out a translation of the items into the target language. Once the two versions were obtained, the entire adaptation team, both separately and as a group, made an assessment of the translation of both versions based on specific verification criteria. These criteria were adapted from Elosua et al. (2014), and can be consulted in the Supplementary Materials (Supplementary Material 13). Subsequently, the team met to discuss the results obtained and agree on a single version. In the refinement process, the adaptation of the items content prevailed, that is, the semantic equivalence over the grammatical. In addition, the format of the test and the instructions were kept faithful to the original. All response alternatives were labeled, since this seems to improve the reliability of the items (Schaeffer \& Presser, 2003). After that, a backward translation was performed. We recruited two new professional translators that independently back-translated the Spanish items into English. After that, the adaptation team agreed on a single version of the back-translated English version. We checked quality translation in two ways: Firstly, we sent the back-translated English version to the authors of the original version, so they could assess the conceptual equivalence between items. Secondly, to assess semantic similarity we performed a new search in the Semantic Scale Network (SNN), with which we expected to find similar results as with the original SOII.

Regarding the first way, the authors of the original SOII gave their approval to the back-translation English version and found no evidence of even minor equivalence concerns. As regards to the second way, we found that the closest "neighbor" to the back-translated English version was the original SOII. Taken all together, these results showed evidence that the translation is suitable regarding cultural and linguist aspects.

\section{Piloting Phase}

The purpose of this phase was to collect the reactions of the people who perform the test, ensure that the items and instructions were correctly understood, record the time necessary for the execution of the questionnaire, collect information on possible errors in content or format which may be corrected and obtain data which will allow carrying out a first item analysis (Elosua et al., 2014; ITC, 2018; Muñiz et al., 2013). For this purpose, a first study was carried out with the version agreed by the translation team. The results of this analysis indicated modifications to this version were necessary. The appropriate changes were made and a second pilot study was carried out.

First Pilot Study. Table 1 shows the descriptive indices of all items of the adapted version (see response frequency distributions in the Supplementary Materials 9 and 10). In self-interest, the means of the items was around five, except for A5, A8 and A9 whose means were around three. In other-interest, the means were all above four, except for O5, O6 and O9). Regarding the frequency distributions, the percentage of responses indicated in alternative 4 (intermediate) exceeded 20\% in three items of the self-interest dimension (A5, A7 and $\mathrm{A} 8)$ and in six of the other-interest dimension $(\mathrm{O} 1, \mathrm{O} 3$, O5, O6, O8 and O9), in several of those rising up to $50 \%$. This may happen in the original test (Gerbasi \& Prentice, 2013), since they obtained means around four in several samples. Not in vain, according to Hernández et al. (2004), the middle category in rating scales should be avoided, since the assumption that all respondents use 
Table 1. Descriptive Statistics Summary of the SOII Items included in the Two Pilot Studies

\begin{tabular}{|c|c|c|c|c|c|c|c|c|c|c|}
\hline & \multicolumn{5}{|c|}{ First pilot study } & \multicolumn{5}{|c|}{ Second pilot study } \\
\hline & Mean & $S D$ & Skew & Kurtosis & $\mathrm{CV}$ & Mean & $S D$ & Skew & Kurtosis & $\mathrm{CV}$ \\
\hline A1 & 5.55 & 1.43 & -0.82 & 0.17 & 0.26 & 4.07 & 1.28 & -0.47 & -.30 & 0.31 \\
\hline $\mathrm{A} 2$ & 5.03 & 1.42 & -0.61 & -0.03 & 0.28 & 3.32 & 1.44 & -0.21 & -0.83 & 0.43 \\
\hline A3 & 5.73 & 1.14 & -.17 & 1.98 & 0.20 & 4.87 & 1.10 & -1.09 & 1.18 & 0.23 \\
\hline $\mathrm{A} 4$ & 5.50 & 1.21 & -0.72 & 0.46 & 0.22 & 4.92 & 1.21 & -1.19 & 1.08 & 0.25 \\
\hline A5 & 2.89 & 1.38 & 0.10 & -0.73 & 0.48 & 2.55 & 1.34 & 0.41 & -0.84 & 0.53 \\
\hline A6 & 5.04 & 1.22 & -0.25 & -0.74 & 0.24 & 4.70 & 1.19 & -0.77 & 0.08 & 0.25 \\
\hline A7 & 4.77 & 1.48 & -0.73 & 0.40 & 0.31 & 3.60 & 1.33 & -0.29 & -0.81 & 0.37 \\
\hline A8 & 3.13 & 1.69 & 0.31 & -0.77 & 0.54 & 2.25 & 1.30 & 0.64 & -0.82 & 0.58 \\
\hline A9 & 2.66 & 1.46 & 0.44 & -0.96 & 0.55 & 2.20 & 1.17 & 0.67 & -0.38 & 0.53 \\
\hline A10 & - & - & - & - & - & 5.04 & 0.97 & -1.27 & 2.48 & 0.19 \\
\hline $\mathrm{O} 1$ & 4.21 & 1.80 & -0.19 & -0.85 & 0.43 & 3.07 & 1.42 & 0.04 & -0.83 & 0.46 \\
\hline $\mathrm{O} 2$ & 6.07 & 0.95 & -1.08 & 1.14 & 0.16 & 4.55 & 1.00 & -0.80 & 1.13 & 0.22 \\
\hline $\mathrm{O} 3$ & 4.45 & 1.44 & -0.59 & 0.21 & 0.32 & 3.64 & 1.30 & -0.17 & -0.62 & 0.36 \\
\hline $\mathrm{O} 4$ & 5.76 & 0.94 & -0.81 & 1.34 & 0.16 & 4.63 & 0.96 & -0.80 & 1.52 & 0.21 \\
\hline O5 & 3.61 & 1.40 & -0.29 & 0.10 & 0.39 & 3.44 & 1.17 & -0.45 & -0.35 & 0.34 \\
\hline O6 & 3.63 & 1.38 & -0.42 & -0.38 & 0.38 & 2.91 & 1.20 & 0.00 & -0.79 & 0.41 \\
\hline $\mathrm{O} 7$ & 5.56 & 1.15 & -0.94 & 1.43 & 0.21 & 3.74 & 1.22 & -0.37 & -0.17 & 0.33 \\
\hline O8 & 4.76 & 1.18 & -0.54 & 1.17 & 0.25 & 4.17 & 1.04 & -0.51 & 0.32 & 0.25 \\
\hline O9 & 3.69 & 1.58 & -0.11 & -0.77 & 0.43 & 3.16 & 1.19 & -0.23 & -0.69 & 0.38 \\
\hline O10 & - & - & - & - & - & 4.33 & 0.99 & -0.39 & 0.14 & 0.23 \\
\hline
\end{tabular}

Note. $\mathbf{C V}=$ Coefficient of variation .

the ordered-response categories in the same way cannot be maintained.

Table 2 shows the comparison of the discrimination indices between the original test and the adaptation. In the adapted inventory, only the item A4 had a value below .30. In order to check for differences in discrimination indices, minimal-effects tests were done. The minimum difference to conclude that the differences are relevant was established at $r=.30$ (moderate difference), since it is the minimum value with which the statistical power of .80 was obtained. Results did not indicate statistically significant differences in the indices of any item. Slight differences were observed in regards to the quartiles of the discrimination coefficients although the original and the adaptation followed a similar trend.

Counter to theoretical expectations (two dimensions), the methods of extracting factors, except the BIC, advised a three-dimensional factor solution. Therefore, two- and three-factor solutions were tested. It was verified that the assumptions of linearity and collinearity were met. As for the adequacy of the data for the EFA, the KMO index was suitable (Lloret-Segura et al., 2014) with a value of .72. Fit indices of the two-factor model were acceptable (RMSEA = .069; RSMR = .09; GFI = .924), and those of the three model were suitable (RMSEA = .015; RSMR = .06; GFI = .969). In the twofactor model, Cronbach's alpha was .72 in self-interest and .78 in other-interest. In the three-factor model, the alpha was .58 in self-interest, .72 in other-interest and .79 in the third unexpected factor.

Based on these results, it can be said that although in general terms the adaptation has good psychometric properties, several problems have been detected in some items, which are unsatisfactory (low discrimination of some items and high accumulation of responses in the intermediate alternative). Moreover, the factor structure revealed a theoretically unexpected third dimension, whose items (A5, A8, A9, O5, O6 and O9) might reflect behaviors related to the pursuit of recognition or consideration. In order to solve this problem, we fitted several models in which we dropped double-loading items (O5, O9, and O6) iteratively. Concerning the number of factors to be retained, parallel analyses suggested again a threefactor solution for all the models without only one of these items. Regarding the factor structure, some loadings were below .30 (e.g., A4, A6, and A7). Only the model without the three items indicated a two-factor solution; however, the item A4 still showed low factor loadings.

For all the above, the following modifications were made in order to solve these problems:

1. Remove the neutral intermediate response alternative ( 4 = "Neither agree nor disagree"). 
Table 2. Comparison of Discrimination Indices between the Original and Adapted SOII

\begin{tabular}{|c|c|c|c|c|c|c|c|c|c|c|}
\hline \multirow[b]{3}{*}{ Item } & \multicolumn{5}{|c|}{ Discrimination } & \multicolumn{5}{|c|}{ Quartile } \\
\hline & \multirow[t]{2}{*}{ Original } & & \multicolumn{3}{|c|}{ Adaptation } & \multirow[t]{2}{*}{ Original } & & \multicolumn{3}{|c|}{ Adaptation } \\
\hline & & $\begin{array}{l}\text { IV } 18 \\
\text { items }\end{array}$ & $\begin{array}{l}\text { RV } 18 \\
\text { items }\end{array}$ & $\begin{array}{l}\text { RV } 20 \\
\text { items }\end{array}$ & $\begin{array}{l}\text { RV } 16 \\
\text { items }\end{array}$ & & $\begin{array}{l}\text { IV } 18 \\
\text { items }\end{array}$ & $\begin{array}{l}\text { RV } 18 \\
\text { items }\end{array}$ & $\begin{array}{l}\text { RV } 20 \\
\text { items }\end{array}$ & $\begin{array}{l}\text { RV } 16 \\
\text { items }\end{array}$ \\
\hline A1 & .40 & .55 & .62 & .62 & .65 & 1 & 3 & 3 & 3 & 4 \\
\hline A2 & .49 & .53 & .37 & .37 & .40 & 2 & 2 & 1 & 1 & 1 \\
\hline $\mathrm{A}^{\mathrm{a}}$ & .56 & .53 & .60 & .63 & .70 & 3 & 2 & 3 & 4 & 4 \\
\hline A4 & .40 & .10 & .25 & .29 & .33 & 1 & 1 & 1 & 1 & 1 \\
\hline A5 & .58 & .57 & .41 & .38 & - & 3 & 3 & 2 & 1 & - \\
\hline $\mathrm{A} 6^{\mathrm{a}}$ & .31 & .31 & .38 & .43 & .48 & 1 & 1 & 1 & 2 & 2 \\
\hline A7 & .60 & .38 & .67 & .66 & .64 & 4 & 1 & 4 & 4 & 3 \\
\hline $\mathrm{A} 8^{\mathrm{a}}$ & .61 & .69 & .67 & .64 & .48 & 4 & 4 & 4 & 4 & 2 \\
\hline A9 & .49 & .57 & .54 & .50 & - & 2 & 4 & 2 & 3 & - \\
\hline $\mathrm{A} 10^{\mathrm{a}}$ & - & - & - & .48 & .56 & - & - & - & 2 & 3 \\
\hline O1 & .53 & .45 & .35 & .38 & .41 & 1 & 1 & 1 & 1 & 1 \\
\hline $\mathrm{O} 2^{\mathrm{a}}$ & .65 & .55 & .50 & .50 & .48 & 3 & 2 & 1 & 1 & 2 \\
\hline $\mathrm{O} 3$ & .67 & .59 & .52 & .55 & .58 & 4 & 3 & 2 & 3 & 2 \\
\hline $\mathrm{O}^{\mathrm{a}}$ & .47 & .51 & .65 & .67 & .67 & 1 & 2 & 4 & 4 & 4 \\
\hline O5 & .66 & .59 & .52 & .51 & - & 3 & 3 & 2 & 2 & - \\
\hline $\mathrm{O} 6^{\mathrm{a}}$ & .76 & .67 & .48 & .46 & .42 & 4 & 4 & 1 & 1 & 1 \\
\hline $\mathrm{O}^{\mathrm{a}}$ & .56 & .50 & .60 & .61 & .62 & 1 & 1 & 3 & 4 & 3 \\
\hline O8 & .59 & .66 & .63 & .63 & .64 & 2 & 4 & 4 & 4 & 3 \\
\hline O9 & .63 & .47 & .54 & .51 & - & 2 & 1 & 3 & 2 & - \\
\hline $\mathrm{O} 10^{\mathrm{a}}$ & - & - & - & .60 & .65 & - & - & & 3 & 4 \\
\hline
\end{tabular}

Note. $\mathrm{IV}=$ Initial Version; RV = Rephrased Version. ${ }^{\mathrm{a}}=$ Modified item from the IV to the RV.

2. Reformulate the following pairs of items (recall that the SOII assesses every socially valued domain with a pair of items for both self- and other-interest behaviors, and that these pairs have a very similar wording): A6-O4, A8-O6 (two different wordings, one more literal and one more free, were proposed for these ones), A4-O2 and A3-O7.

All the item changes can be consulted in the Supplementary Material 1 . The selection of the items for the final version was decided based on the consideration on their content and on the discrimination indices obtained with the different sets of items that could be formed according to the proposed modifications (see in Appendix 1). Likewise, special care was taken of the similarity between the pairs of items of the two dimensions. Based on these considerations, it was decided to include all the modifications. The free wording for A6 was discarded and the free wording for the pair A8-O6 was included in order to better capture the meaning of the item in English. Therefore, the following analyses include a 20-items version of the test, ten items per dimension.

Second Pilot Study. All the modifications made managed to improve the psychometric problems of the items of the initial version (see response frequency distributions in the Supplementary Materials 11 and 12). In the rephrased version, the means of the items showed a similar trend, and the variability was higher than in the first pilot study, as estimated with the coefficient of variation (see Table 1). Except for A4 in the 18- and 20-items versions, all items obtained suitable discrimination indices (see Table 2). It should be highlighted that in the original test in English this item presented the second lowest discrimination coefficient. Regarding the minimal-effects tests, results did not indicate statistically significant differences in the indices of any item. In the quartiles of discrimination comparison between versions, after making the changes, the distribution of the rephrased version is less like the original version than that of the initial adapted version. This can be explained by the removal of the intermediate alternative and the fact that some of the items with greater discrimination in the original (e.g., A8) were modified in the adaptation based on the results of the first EFA.

The EFA results are shown in Tables 3 and 4. Again, the methods of factor extraction advised a factor solution between two and three dimensions. The assumptions of linearity and collinearity were fulfilled and the $\mathrm{KMO}$ index was suitable with a value of .77. As in the first pilot study, the three-factor models (Model 2 and 4) 
Table 3. Fit Indices of the Two and Three-Factor Models

\begin{tabular}{|c|c|c|c|c|c|c|}
\hline & \multicolumn{3}{|c|}{2 factors } & \multicolumn{3}{|c|}{3 factors } \\
\hline & $\begin{array}{l}\text { Model } 1 \\
\text { (18 items) }\end{array}$ & $\begin{array}{c}\text { Model } 3 \\
\text { (20 items) }\end{array}$ & $\begin{array}{c}\text { Model } 5 \\
\text { (16 items) }\end{array}$ & $\begin{array}{c}\text { Model } 2 \\
\text { (18 items) }\end{array}$ & $\begin{array}{c}\text { Model } 4 \\
\text { (20 items) }\end{array}$ & $\begin{array}{c}\text { Model } 6 \\
\text { (16 items) }\end{array}$ \\
\hline RMSEA 90\% CI & $.087[.080, .100]$ & $.086[.057, .100]$ & $.056[.055, .061]$ & $.039[.001, .005]$ & $.027[.001, .005]$ & $.051[.017, .054]$ \\
\hline RSMR & .09 & .09 & .07 & .06 & .06 & .06 \\
\hline GFI & .935 & .923 & .962 & .973 & .971 & .976 \\
\hline
\end{tabular}

Note. RMSEA has been estimated by Weighted Least Squares adjusted by the Mean and the Variance (WLS-MV).

obtained better results in the fit indices than that of twofactor models (Model 1 and 3), with the latter ones achieving acceptable values. The exploration of the EFA residuals (see in the Supplementary Materials 3 to 6) revealed a normal distribution in the four models. In Model 1 and 3 some excessive maximum residuals were observed $(\approx 3)$, which may suggest misspecifications (Ferrando \& Lorenzo-Seva, 2013). Specifically, the items with the highest residuals were those related to the third factor (A5-O5, A9-O9).

Table 4 shows the Cronbach's alpha coefficients and the factor loadings of the four models. The loadings of the items in the two-factor models (Model 1 and 3) correspond to the theoretical model. Only the item A4 is below $(<.30)$ of the minimal recommended values (Bandalos, 2018). It should be noted that this item obtained a low discrimination index. In the solution of three factors (Model 2 and 4) it was observed that five items loaded on the third theoretically unexpected factor. Three of them were items that theoretically are indicators of self-interest (A5, A8 and A9), and the other two, of other-interest (O6 and O9). The content of these items deals with behaviors that might be related to the search for recognition or consideration. These results suggest that the three-factor models (Model 2 and 4) are better than the two-factor models (Model 1 and 3), since it presented a better fit to the data, and the factor loadings were suitable in general and theoretically interpretable (although unexpected).

Despite this result, and with the purpose of obtaining a better factor solution according to the theoretical model, it was decided to remove, one by one, the items of the two pairs that presented the highest residuals, and then performing a new EFA. In this EFA with eight items per theoretical dimension (16-items version), the extracting factors methods indicated a two-factor solution. However, a two-factor model (Model 5) and a three-factor model (Model 6) were tested (see Table 3). The fit indices showed suitable and similar values for these two models. Factor correlations in all models can be seen in Table 4.
In Model 5, the factor loadings of all the items are appropriately distributed according to their theoretical factor (see Table 4). However, the loadings of Model 6 did not show a theoretically interpretable pattern. In addition, only three items represented the third factor. The exploration of the residuals did not reveal problems in any of these models (see in the Supplementary Materials 7 and 8). In terms of reliability, self-interest and the third dimension of Model 6 were the only ones that showed a coefficient below recommendations (Nunnally \& Berstein, 1995). Based on these results, the two-factor model appears to be more appropriate than the three-factor model in the 16-items version, since, although both showed a good fit to the data, the factor loadings of the three-factor model were not theoretically interpretable and some reliability coefficients were low.

\section{Discussion}

Self-interest is a relevant individual characteristic to understand human behavior in society. Traditionally, researchers have placed self-interest at the center of their explanatory theories. However, there are other factors which influence social behavior such as other-interest (e.g., Dovidio et al., 2017; Fehr et al., 2002; Fehr \& Gächter, 2000; Schroeder et al., 1995). Gerbasi and Prentice (2013) have proposed a conceptualization that overcomes the problem of the centrality of self-interest and assumes that this construct and other-interest are not independent nor necessarily opposed.

In this vein, they developed the Self- and OtherInterest Inventory (SOII) with the purpose of measuring both constructs. The SOII was developed in the United States and has shown good psychometric properties in several applications. However, there is no equivalent test in Spanish; hence, the aim of this work is to present the adaptation of the SOII to Spanish university students.

As noted by Elosua et al. (2014), the test adaptation is not simply a linguistic nor strictly a quantitative issue. It requires the conjunction of legal, cultural, conceptual, 
Table 4. Reliability, Factor Correlations and Factor Loadings of the Items in the Solution of Two and Three Factors

\begin{tabular}{|c|c|c|c|c|c|c|c|c|c|c|c|c|c|c|c|}
\hline \multirow[b]{3}{*}{ Item } & \multicolumn{5}{|c|}{18 items } & \multicolumn{5}{|c|}{20 items } & \multicolumn{5}{|c|}{16 items } \\
\hline & \multicolumn{2}{|c|}{ Model 1 (2 factors) } & \multicolumn{3}{|c|}{ Model 2 (3 factors) } & \multicolumn{2}{|c|}{ Model 3 (2 factors) } & \multicolumn{3}{|c|}{ Model 4 (3 factors) } & \multicolumn{2}{|c|}{ Model 5 (2 factors) } & \multicolumn{3}{|c|}{ Model 6 (3 factors) } \\
\hline & $\mathrm{F} 1$ & $\mathrm{~F} 2$ & F1 & $\mathrm{F} 2$ & F3 & F1 & F2 & $\mathrm{F} 1$ & F2 & F3 & F1 & $\mathrm{F} 2$ & F1 & $\mathrm{F} 2$ & F3 \\
\hline A1 & .639 & -.072 & .717 & -.125 & .046 & .666 & -.085 & .623 & -.019 & .196 & .711 & -.100 & .538 & -.110 & .249 \\
\hline $\mathrm{A} 2$ & .386 & -.262 & .246 & -.277 & .152 & .392 & -.259 & .282 & -.270 & .154 & .412 & -.295 & .287 & -.296 & .144 \\
\hline A3 & .524 & .030 & .749 & -.022 & -.090 & .579 & .044 & .717 & .029 & .041 & .679 & .036 & .716 & .027 & .040 \\
\hline A4 & .227 & .068 & .410 & .043 & -.130 & .276 & .075 & .420 & .075 & -.062 & .352 & .058 & .508 & .058 & -.138 \\
\hline A5 & .493 & .038 & .085 & .025 & .536 & .454 & .000 & .053 & -.045 & .555 & - & - & - & - & - \\
\hline A6 & .423 & -.208 & .356 & -.230 & .095 & .450 & -.188 & .420 & -.199 & .101 & .501 & -.210 & .375 & -.213 & .164 \\
\hline A7 & .703 & .053 & .594 & .010 & .247 & .702 & .022 & .494 & -.016 & .381 & .671 & .015 & .278 & -.007 & .563 \\
\hline A8 & .675 & -.056 & .190 & -.079 & .633 & .662 & -.13 & .182 & -.191 & .674 & .525 & -.169 & .039 & -.205 & .667 \\
\hline A9 & .571 & -.046 & -.083 & -.063 & .862 & .541 & -.120 & -.050 & -.200 & .814 & - & - & - & - & - \\
\hline A10 & - & - & - & - & - & .460 & .119 & .657 & .114 & -.039 & .562 & .124 & .716 & .121 & -.089 \\
\hline O1 & .221 & .298 & .381 & .276 & -.062 & .232 & .337 & .337 & .329 & .016 & .282 & .334 & .251 & .324 & .106 \\
\hline $\mathrm{O} 2$ & -.179 & .579 & -.021 & .575 & -.068 & -.017 & .579 & -.060 & .570 & -.032 & -.147 & .552 & -.036 & .544 & -.069 \\
\hline $\mathrm{O} 3$ & .153 & .532 & .340 & .515 & -.050 & .180 & .567 & .302 & .553 & .035 & .213 & .577 & .233 & .563 & .075 \\
\hline $\mathrm{O} 4$ & -.124 & .745 & .005 & .732 & .006 & -.105 & .755 & -.007 & .734 & .034 & -.083 & .733 & -.066 & .717 & .078 \\
\hline O5 & -.023 & .504 & -.220 & .525 & .310 & -.037 & .483 & -.209 & .470 & .281 & - & - & - & - & - \\
\hline O6 & .394 & .422 & .139 & .406 & .423 & .367 & .390 & .087 & .352 & .475 & .283 & .340 & -.124 & .337 & .597 \\
\hline O7 & .026 & .640 & .126 & .621 & .041 & .039 & .641 & .082 & .617 & .104 & .036 & .650 & -.020 & .635 & .166 \\
\hline O8 & -.234 & .712 & -.060 & .703 & -.065 & -.222 & .713 & -.093 & .698 & .032 & -.218 & .736 & -.164 & .721 & .023 \\
\hline O9 & .224 & .489 & -.129 & .510 & .533 & .199 & .415 & -.175 & .394 & .558 & - & - & - & - & - \\
\hline $\mathrm{O} 10$ & - & - & - & - & - & -.111 & .657 & .178 & .671 & -.195 & -.044 & .675 & .178 & .681 & -.180 \\
\hline$\alpha$ & .74 & .77 & .68 & .75 & .74 & .76 & .79 & .72 & .76 & .73 & .75 & .77 & .68 & .76 & .59 \\
\hline$r_{F 1}$ & 1 & & 1 & & & 1 & & 1 & & & 1 & & 1 & & \\
\hline$r_{\mathrm{F} 2}$ & .15 & 1 & .07 & 1 & & .18 & 1 & .03 & 1 & & .19 & 1 & .09 & 1 & \\
\hline$r_{\mathrm{F} 3}$ & - & - & .37 & -.05 & 1 & - & - & .23 & .07 & 1 & - & - & .46 & .08 & 1 \\
\hline
\end{tabular}

Note. $\mathrm{F} 1=$ Self-interest factor; F2 = Other-interest factor; $\mathrm{F} 3=$ Factor related to attract attention and stand out from other people; $r_{\mathrm{F} 1}=$ Factor correlation with F1; $r_{\mathrm{F} 2}=\mathrm{Factor}$ correlation with $\mathrm{F} 2$; $r_{\mathrm{F} 3}=$ Factor correlation with F3.

The most relevant factor loadings for each factor have been high lighted in bold so that the reader can better appreciate the result. 
linguistic and metric aspects. In this sense, not only the adaptation of the SOII is presented (see in the Supplementary Materials 1) but also the first steps of the adaptation process are explained.

Regarding the above mentioned aspects, contacting the authors of the original test and obtaining the ethical certificate for the investigation guaranteed compliance with the legal aspects. Secondly, the nomological networks of the construct were studied through a systematic search, an empirical search of semantic similarity and a theoretical study, of which there were no signs of a discrepancy between the construct in the original and target cultures. Subsequently, a cultural and linguistic adaptation was carried out, using both iterative forward and back-translation designs with a team of experts and professional translators. Finally, empirical procedures were used to obtain initial evidence of some psychometric properties.

In general, the psychometric properties of the adaptation were acceptable (discrimination, internal structure and reliability). However, the more specific analysis revealed problems with discrimination indices and frequency distributions in some items. Moreover, the EFA suggested that, although the internal structure fits reasonably well to the theoretical model of two factors (self-interest and other-interest), there is another three-factor model with better results. The six items that formed this third unexpected factor were theoretically interpretable, since they all dealt with behaviors related to the pursuit of recognition or consideration. As selfinterest is defined in this work, the pursuit of recognition is one of the socially valued domains related to the pursuit for personal gains (Gerbasi \& Prentice, 2013). The fact that these items are grouped into a single factor may suggest that this aspect is overrepresented in the test.

Due to these results, it was decided to modify the problematic aspects and carry out a second pilot study. All changes were made taking into account the original test in English. Firstly, the intermediate alternative was removed ( $4=$ "Neither agree nor disagree"). In this sense, several studies (Lozano et al., 2008; Schaeffer \& Presser, 2003) discourage the use of response scales with a neutral intermediate alternative, because they tend to concentrate the responses of the participants on it and this may affect to the reliability and internal structure of the test. In addition, the use of a middle category has been discouraged, since it violates the assumption that response categories are ordered (Hernández et al., 2004). Secondly, the wording of several items was modified: A4 and A6 to improve their discrimination indices, $\mathrm{A} 3, \mathrm{O} 2, \mathrm{O} 4$ and $\mathrm{O} 7$ to improve their variability, and the pair A8-O6 to improve the factor loadings in its theoretical dimension. For the pairs A3-O7 and A8-O6, two different drafting changes were proposed (one freer translation and the other more literal with respect to the original in English). For the first pair, the freer wording was discarded because it did not imply an improvement in the discrimination or in the comprehension of the content of the original ("Getting good grades is near the top of my priorities"). For the second pair, both wordings were included because they had good discrimination indices improved the goodness of fit in the EFA and it may favor a better understanding of the original item ("I am constantly looking for ways to get ahead"). Therefore, 20-items version was developed.

These modifications mitigated the psychometric problems of the items. The variability of the items was higher than in the first study, and all the items, with the exception of A4 in the 18-items and 20-item versions, showed good discrimination coefficients. Not in vain, A4 presented the second lowest discrimination coefficient in the original test. The distribution of discrimination indices of the items, before the modifications, tended to be similar to the original. Furthermore, the discrimination indices were not statistically different between the original and the adaptation in all items. These results suggest that the items have a similar discriminative capacity in both contexts.

The reliability indices were suitable in all models, except for some factors in the three-factor solutions. Considering the internal structure, the EFA showed again that the solution of three factors presented better results than the two factors. However, the distribution of factor loadings in the two-factor model and the fit indices were acceptable. For this reason and because the items with the highest standardized residuals were those related to the third factor (A5-O5, A9-O9), it was decided to check another model without these items. The new EFA with the 16-items version showed that the two-factor model fits the data adequately and the factor loadings are distributed according to the theoretical model. The three-factor model fitted well with the data, but the factor loadings of the items were not distributed according to any theoretically interpretable cluster. In terms of reliability, adequate coefficients were obtained in the two-factor model, but in two factors of the three-factor model, it was below the recommended value (Nunnally \& Berstein, 1995).

This improvement of the two-factor model without the pairs of items A5-O5 and A9-O9 seems to suggest that the recognition pursuit aspect of the operational definition is overrepresented in the adaptation of 18 and 20 items, and possibly in the original test. The other specific aspects (i.e., academic successes, social status, material goods and happiness) are only represented with one item. By removing these four items (two per factor), all aspects of the construct are matched in the 
number of indicators and new factors whose items correlate highly with each other are not formed.

The current study has some limitations. On the one hand, some EFA fit indices may be affected because the sample is small. However, the sample size is acceptable for the piloting phase in the test adaptation (Elosua et al., 2014; Muñiz et al., 2013). On the other hand, the representativeness of the sample may be limited, due to non-random sampling, sample size, and the characteristics of the participants themselves (e.g., the student sample degree).

In future research, attention should be paid to these aspects and replications should be made with larger, more heterogeneous samples and using probabilistic sampling techniques. Likewise, future studies must be carried out to confirm the factor structure of the test, the invariance between the original and target cultures as well as to obtain evidence of convergent and discriminant validity.

The results of the SOII adaptation to Spanish students suggest that it is an instrument with good psychometric properties. Item discrimination, reliability and internal validity indices were kept within suitable ranges. Results in discrimination and reliability suggest that it can be used for research purposes. In relation to internal validity, the original test showed a structure of two factors (Gerbasi \& Prentice, 2013). In the adaptation, two solutions were obtained that could be valid empirically, one of two factors and another of three. In the adapted 18-items and 20-items version, the three-factor model obtained better results than the two-factor model. This result does not support what was found in the original, although the three-factor model was not checked. In the adapted 16-items version, the two-factor model was better in terms of internal validity and reliability.

Taking into account the results obtained and the theoretical starting model (Gerbasi \& Prentice, 2013; Urbina \& Ruiz-Villaverde, 2019), the adapted 16-items version seems to have better psychometric properties. However, these results should be taken with caution as they are based only on exploratory analyses with small sample sizes. Hence, the 18 -items and 20 -items version are also presented so that the study of the factor structure can be deepened further.

In short, the Spanish adaptation of the SOII to academic settings shows initial evidence of adequate psychometric properties, similar to the original test. If these results are confirmed in future studies, the SOII may be a very useful tool for social scientists - especially economists and psychologists - in the research on selfinterest and other-interest when explaining individual behavior in society. The SOII covers the need of a valid and reliable measurement instrument in the Spanish culture that assesses personal interests overcoming the traditional conceptualization of self-interest as opposed to other-interest as central in individual behavioral research. Future research will be able to enhance our knowledge in a variety of topics, such as relationships between psychosocial attributes, cross-cultural research and effects of indoctrination and selection in economic education.

\section{Supplementary Material}

To view supplementary material for this article, please visit http:/ / dx.doi.org/10.1017/SJP.2021.29.

\section{References}

Ato, M., López-García, J. J., \& Benavente, A. (2013). Un sistema de clasificación de los diseños de investigación en psicología [A classification system for research designs in psychology]. Anales de Psicología, 29(3), 1038-1059. https: / / doi.org/10.6018/analesps.29.3.178511.

Balluerka, N., Gorostiaga, A., Alonso-Arbiol, I., \& Haranburu, M. (2007). La adaptación de instrumentos de medida de unas culturas a otras: Una perspectiva práctica [The adaptation of measuring instruments from one culture to another: A practical perspective]. Psicothema, 19(1), 124-133.

Bandalos, D. L. (2018). Measurement theory and applications for the social sciences. Guilford Publications.

Batson, C. D. (1998). Altruism and prosocial behavior. In D. A Schroeder, L. A. Penner, J. F. Dovidio, \& J. A. Piliavin (Eds.), The psychology of helping and altruism: Problems and puzzles. McGraw-Hill.

Batson, C. D., Duncan, B. D., Ackerman, P., Buckley, T., \& Birch, K. (1981). Is empathic emotion a source of altruistic motivation? Journal of Personality and Social Psychology, 40(2), 290-302. https: / / doi.org/10.1037/ /0022-3514.40.2.290.

Camerer, C. F. (2011). Behavioral game theory: Experiments in strategic interaction. Princeton University Press.

Camerer, C. F., \& Thaler, R. H. (1995). Ultimatums, dictators and manners. Journal of Economic Perspectives, 9, 209-219.

Charness, G., \& Dufwenberg, M. (2006). Promises and partnership. Econometrica, 74(6), 1579-1601. http://doi.org/ 10.1111/j.1468-0262.2006.00719.x.

Cialdini, R. B. (1991). ¿Altruismo o egoísmo? Esa es (todavía) la cuestion [Altruism or selfishness? That is (still) the question]. Investigación Psicológica, 2(2), 124-126.

Diedenhofen, B., \& Musch, J. (2015). cocor: A comprehensive solution for the statistical comparison of correlations. PLoS ONE, 10(4), Article e0121945. https: / / doi.org/10.1371/ journal.pone.0121945.

Dovidio, J. F., Piliavin, J. A., Schroeder, D. A., \& Penner, L. A. (2017). The social psychology of prosocial behavior. Psychology Press. https:/ / doi.org/10.4324/9781315085241.

Elosua, P., Mujika, J., Almeida, L. S., \& Hermosilla, D. (2014). Procedimientos analítico-racionales en la adaptación de tests. Adaptación al español de la batería de pruebas de razonamiento [Judgmental-analytical procedures for adapting tests: Adaptation to Spanish of the Reasoning Tests Battery]. Revista Latinoamericana de Psicología, 46(2), 117-126. https: / /doi.org/10.1016/s0120-0534(14)70015-9. 
Fehr, E., \& Gächter, S. (2000). Fairness and retaliation: The economics of reciprocity. Journal of Economic Perspectives, 14(3), 159-181. https://doi.org/10.1257/jep.14.3.159.

Fehr, E., Fischbacher, U., \& Gächter, S. (2002). Strong reciprocity, human cooperation, and the enforcement of social norms. Human Nature, 13(1), 1-25. https:/ / doi.org/ 10.1007/s12110-002-1012-7.

Fehr, E., \& Schmidt, K. M. (1999). A theory of fairness, competition, and cooperation. The Quarterly Journal of Economics, 114(3), 817-868. http:/ / doi.org/10.1162/ 003355399556151.

Ferrando, P. J., \& Lorenzo-Seva, U. (2013). Unrestricted item factor analysis and some relations with item response theory. Technical report. Departament de Psicologia Universitat Rovira i Virgili. https:/ / psico.fcep.urv.cat/utilitats/factor/ documentation/technicalreport.pdf.

Frank, R. H., Gilovich T., \& Regan, D. T. (1993). Does studying economics inhibit cooperation? Journal of Economic Perspectives, 7(2), 159-171. https: / / doi.org/10.1257/jep.7.2.159.

Frey, B. S., \& Meier, S. (2003). Are political economists selfish and indoctrinated? Evidence from a natural experiment. Economic Inquiry, 41(3), 448-462. https:/ / doi.org/10.1093/ei/cbg020.

Gerbasi, M. E., \& Prentice, D. A. (2013). The Self-and OtherInterest Inventory. Journal of Personality and Social Psychology, 105(3), 495-514. https:/ / doi.org/10.1037/a0033483.

Hernández, A., Drasgow, F., \& González-Romá, V. (2004). Investigating the functioning of a middle category by means of a mixed-measurement model. Journal of Applied Psychology, 89(4), 687-699. https:/ / doi.org/10.1037/0021-9010.89.4.687.

Hirschman, A. O. (1985). Against parsimony: Three easy ways of complicating some categories of economic discourse. Economics and Philosophy, 1(1), 7-21. http:/ / doi.org/ $10.1017 /$ S0266267100001863.

Hirschman, A. O. (1997). The passions and the interests: Political arguments for capitalism before its triumph. Princeton University Press.

International Test Commission. (2018). ITC guidelines for translating and adapting tests (Second Edition). International Journal of Testing, 18(2), 101-134. https: / / doi.org/10.1080/ 15305058.2017.1398166.

Izquierdo, I., Olea, J., \& Abad, F. J. (2014). Exploratory factor analysis in validation studies: Uses and recommendations. Psicothema, 26(3), 395-400. https:/ / doi.org/10.7334/ psicothema2013.349.

Lemon, J., \& Grosjean, P. (2015). prettyR: Pretty Descriptive Stats (R package version 2.2.) https:/ /CRAN.R-project.org/ package=prettyR.

Lloret-Segura, S., Ferreres-Traver, A., Hernández-Baeza, A., \& Tomás-Marco, I. (2014). El análisis factorial exploratorio de los ítems: Una guía práctica, revisada y actualizada [Exploratory Item Factor Analysis: A practical guide revised and updated]. Anales de Psicología, 30(3), 1151-1169. https: / / doi.org/10.6018/analesps.30.3.199361.

Lorenzo-Seva, U., \& Ferrando, P. J. (2013). FACTOR 9.2: A comprehensive program for fitting exploratory and semiconfirmatory factor analysis and IRT models. Applied Psychological Measurement, 37(6), 497-498. https: / / doi.org/ $10.1177 / 0146621613487794$.

Lozano, L. M., García-Cueto, E., \& Muñiz, J. (2008). Effect of the number of response categories on the reliability and validity of rating scales. Methodology, 4(2), 73-79. https:/ / doi.org/10.1027/1614-2241.4.2.73.

Mardia, K. V. (1970). Measures of multivariate skewnees and kurtosis with applications. Biometrika, 57, 519-530. https:// doi.org/10.1093/biomet/57.3.519.

Muñiz, J., Elosua, P., \& Hambleton, R. K. (2013). Directrices para la traducción y adaptación de los tests: Segunda edición [Guidelines for test translation and adaptation: Second edition]. Psicothema, 25(2), 151-157. https: / / doi.org/ 10.7334/psicothema2013.24.

Murphy, K. R., Myors, B., \& Wolach, A. (2014). Statistical power analysis: A simple and general model for traditional and modern hypothesis tests ( $4^{\text {th }}$ Ed.). Routledge. https: / / doi.org/ 10.4324/9781315773155.

Myers, D. G., \& Twenge, J. M. (2017). Exploring social psychology. McGraw Hill.

Nunnally, J. C., \& Bernstein, I. J. (1995). Psychometric theory. McGraw Hill.

R Core Team. (2018). R: A language and environment for statistical computing. $R$ Foundation for Statistical Computing. Austria. https: / / www.R-project.org/.

Rabin, M. (1993). Incorporating fairness into game theory and economics. The American Economic Review, 1281-1302.

Revelle W. (2020). psych: Procedures for Psychological, Psychometric, and Personality Research (R package version 2.0.12.) https: / /CRAN.R-project.org / package=psych.

Revelle, W., \& Rocklin, T. (1979). Very simple structure: An alternative procedure for estimating the optimal number of interpretable factors. Multivariate Behavioral Research, 14, 403-414. https: / / doi.org/10.1207/ s15327906mbr1404_2.

Rosenbusch, H., Wanders, F., \& Pit, I. L. (2020). The Semantic Scale Network: An online tool to detect semantic overlap of psychological scales and prevent scale redundancies. Psychological Methods, 25(3), 380-392. https://doi.org/ $10.1037 /$ met0000244.

Schaeffer, N. C., \& Presser, S. (2003). The science of asking questions. Annual Review of Sociology, 29(1), 65-88. https: / / doi.org/10.1146/annurev.soc.29.110702.110112.

Schroeder, D. A., Penner, L. A., Dovidio, J. F., \& Piliavin, J. A. (1995). The psychology of helping and altruism: Problems and puzzles. McGraw-Hill.

Schwarz, G. (1978). Estimating the dimension of a model. The Annals of Statistics, 6(2), 461-464. http:/ / doi.org/10.1214/ aos/1176344136.

Thaler, R. H. (1988). Anomalies: The ultimatum game. Journal of Economic Perspectives, 2, 195-206. http: / / doi.org/10.1257/ jep.2.4.195.

Timmerman, M. E., \& Lorenzo-Seva, U. (2011). Dimensionality assessment of ordered polytomous items with parallel analysis. Psychological Methods, 16(2), 209-220. https://doi.org/10.1037/a0023353.

Urbina, D. A., \& Ruiz-Villaverde, A. (2019). A critical review of homo economicus from five approaches. American Journal of Economics and Sociology, 78(1), 63-93. https:/ / doi.org/ 10.1111/ajes.12258.

Velicer, W. F. (1976). Determining the number of components from the matrix of partial correlations. Psychometrika, 41, 321-327. https: / / doi.org/10.1007/bf02293557. 


\section{Appendix 1. Spanish version of the SOII}

Please answer all the questions with the utmost sincerity. There are no right or wrong answers. Indicate the degree to which you agree with the behaviors that appear in the following statements. Use the following scale to answer:

\begin{tabular}{|c|c|c|c|c|c|c|c|c|c|c|}
\hline 1 & 2 & 3 & 4 & 5 & \multicolumn{6}{|c|}{6} \\
\hline $\begin{array}{l}\text { Completamente en } \\
\text { desacuerdo }\end{array}$ & $\begin{array}{l}\text { Bastante en } \\
\text { desacuerdo }\end{array}$ & $\begin{array}{l}\text { Algo en } \\
\text { desacuerdo }\end{array}$ & $\begin{array}{l}\text { Algo de } \\
\text { acuerdo }\end{array}$ & $\begin{array}{l}\text { Bastante de } \\
\text { acuerdo }\end{array}$ & \multicolumn{6}{|c|}{$\begin{array}{l}\text { Completamente de } \\
\text { acuerdo }\end{array}$} \\
\hline \multicolumn{5}{|c|}{ Busco formas para que mis amigos puedan ganar más dinero. } & 1 & 2 & 3 & 4 & 5 & \\
\hline \multicolumn{5}{|c|}{ Ganar mucho dinero es uno de mis objetivos en la vida. } & 1 & 2 & 3 & 4 & 5 & 6 \\
\hline \multicolumn{5}{|c|}{ Busco constantemente formas de que las personas que conozco progresen. } & 1 & 2 & 3 & 4 & 5 & 6 \\
\hline \multicolumn{5}{|c|}{ Busco oportunidades para ayudar a la gente que conozco a aumentar su estatus social. } & 1 & 2 & 3 & 4 & 5 & 6 \\
\hline \multicolumn{5}{|c|}{ Conseguir buenas notas es una de mis mayores prioridades en la universidad. } & 1 & 2 & 3 & 4 & 5 & 6 \\
\hline \multicolumn{5}{|c|}{ Deseo que mis compañeros de clase me elogien. } & 1 & 2 & 3 & 4 & 5 & 6 \\
\hline \multicolumn{5}{|c|}{ Busco constantemente lo que me hace feliz a mí. } & 1 & 2 & 3 & 4 & 5 & 6 \\
\hline \multicolumn{5}{|c|}{ Busco constantemente la forma de conseguir que las personas que conozco destaquen sobre los demás. } & 1 & 2 & 3 & 4 & 5 & 6 \\
\hline \multicolumn{5}{|c|}{ Busco oportunidades para aumentar mi estatus social. } & 1 & 2 & 3 & 4 & 5 & 6 \\
\hline \multicolumn{5}{|c|}{ Busco constantemente formas de progresar. } & 1 & 2 & 3 & 4 & 5 & 6 \\
\hline \multicolumn{5}{|c|}{ Intento asegurarme de que mis compañeros de clase se enteren de mis éxitos. } & 1 & 2 & 3 & 4 & 5 & 6 \\
\hline \multicolumn{5}{|c|}{ Ayudo a los compañeros que conozco a ir bien en sus estudios. } & 1 & 2 & 3 & 4 & 5 & 6 \\
\hline \multicolumn{5}{|c|}{ Intento ayudar a mis compañeros de clase hablando de sus éxitos. } & 1 & 2 & 3 & 4 & 5 & 6 \\
\hline \multicolumn{5}{|c|}{ Busco constantemente la forma de destacar sobre los demás. } & 1 & 2 & 3 & 4 & 5 & 6 \\
\hline \multicolumn{5}{|c|}{ Miro por mi interés individual. } & 1 & 2 & 3 & 4 & 5 & 6 \\
\hline \multicolumn{5}{|c|}{ Ayudo a los demás a que sean felices. } & 1 & 2 & 3 & 4 & 5 & 6 \\
\hline \multicolumn{5}{|c|}{ Deseo que elogien a mis compañeros de clase. } & 1 & 2 & 3 & 4 & 5 & 6 \\
\hline \multicolumn{5}{|c|}{ Tener éxito es uno de mis objetivos en la vida. } & 1 & 2 & 3 & 4 & 5 & 6 \\
\hline \multicolumn{5}{|c|}{ Miro por los intereses de los demás. } & 1 & 2 & 3 & 4 & 5 & \\
\hline \multicolumn{5}{|c|}{ Ayudar a que mis amigos tengan éxito es uno de los objetivos de mi vida. } & 1 & 2 & 3 & 4 & 5 & 6 \\
\hline
\end{tabular}

